TURIZAM

Volume 25 , Issue 2 96-109 (2021)

ORIGINAL

SCIENTIFIC PAPER

\title{
Impact of the European Capital of Culture Project on the Image of the City of Novi Sad - the Perception of the Local Community
}

\author{
Sanja KovačićA*, Miroslav D. VujičićA, Jovana Čikić ${ }^{B}$, Ivana ŠagovnovićA, \\ Uglješa Stankov ${ }^{A}$, Tamara Zelenović Vasiljevićc \\ Received: July 2020 | Accepted: November 2020 \\ DOI: 10.5937/turizam25-27480
}

\begin{abstract}
Nowadays, the research focus is mainly on how tourists perceive the destination image, while the local community, as a very important key actor, is very often neglected in the studies. In light of the fact that Novi Sad has been declared the European Capital of Culture 2021, great attention has been placed on the local community and its perception of the European Capital of Culture (ECoC) influence on all aspects of the city's life, including city image. In this regard, during April and May 2018, a survey of residents of Novi Sad was conducted to explore their perception of the city's image - cognitive, affective, and overall. Moreover, the paper is focused on identifying the differences in the image perception on the basis of the respondents' socio-demographic characteristics. In this study, which is the beginning of a longitudinal study aiming to follow the influence of the ECoC project on the city image, a total of 797 respondents participated. The results of the research on the cognitive image indicate that the local community mostly agrees with the claims that Novi Sad is a pleasant place to live in, that it has a good gastronomic offer, is an attractive place for education, and that people are kind and hospitable. On the other hand, the smallest degree of agreement is observed with claims which refer to the living standard in the city. When it comes to tourism and culture, significant differences are observed between individual attributes. Also, research on the affective image shows that the city is perceived as relaxing, pleasant, exciting, and lively.The paper also shows that residents sociodemographic characteristics (age, education, monthly income, employment status) influence the image perception.
\end{abstract}

Keywords: image perception, local community, European Capital of Culture, Novi Sad

A Department of Geography, Tourism and Hotel Management, Faculty of Sciences, University of Novi Sad, 21000, Serbia

B Department of Sociology, Faculty o Philosophy, University of Novi Sad, Novi Sad, 21000, Serbia

c Foundation "Novi Sad 2021 - European Capital of Culture",Novi Sad, 21000, Serbia

Corresponding author: sanja.bozic@dgt.uns.ac.rs 


\section{Introduction}

Nowadays, cities are fighting for their recognition at many different levels such as economic development, investment, tourism development, living standard and quality of life, etc. Building a good image, both in the eyes of citizens and tourists is of particular importance in cities that lack a developed industry or some other factors of development and positive transformation. The process of branding a city can enable cities to make their tangible but also intangible attributes recognizable (Kovačić et al., 2019a). Also, a well-positioned brand has the power to bring together all key actors, including citizens around a recognizable urban identity, who will communicate to the target audience (Merrilees et al., 2012).

If we look at a brand as a set of associations in the minds of consumers (Keller, 1993), which in case of a city can be various target groups, it is evident that branding is a complex process consisting of several different aspects (Kovačić et al., 2019b). The branding of a place differs in this respect from the branding of a destination, as a destination brand represents only one of its segments. While place branding is focused on all target groups such as residents, companies and tourists (Kerr, 2006; Braun et al., 2013; Palmer et al., 2013; Zenker, Petersen, 2014), destination branding is focused on brand perception by tourists, and this is precisely the focus of the largest number of studies that investigate brand perception (Jovanović et al., 2017; Kovačić et al., 2019b). Of course, cities are considered as a very complex brand (Zenker et al., 2017). Lynch (1960) argues that people receive various signals through buildings, public space, art, street design, people, personal experiences, or the experiences of friends/acquaintances. All of these factors are potential associations in the minds of the target audience, whether they are tourists, citizens, or investors/industry (Zenker et al., 2017). However, research on residents' perception of the city image is quite obscure and neglected, compared to the research focusing on tourists' perception of the city image (Braun et al., 2013; Dinnie, 2011; Merrilees et al., 2009; Zenker, Erfgen, 2014).

The title of European Capital of Culture, in addition to the transformation of a city in economic, social and cultural terms, greatly contributes to building a brand and recognizability of the city, because the title itself is a recognizable brand (Vujičić et al., 2018; Vasiljević et al., 2018). The first longitudinal study of the impact of the European Capital of Culture on various aspects of city transformation, but especially on image and brand, was conducted in Liverpool in the period 2005-2010, which confirmed the importance of this title for brand development, both in the eyes of tourists and other key actors including citizens. In this regard, and in light of the fact that Novi Sad was declared the European Capital of Culture 2021, great attention is paid to the perception of all key actors on the image of the city and their inclusion in all aspects of city life. A special focus of this study is the perception of the image by the local community - the citizens of the city, and the ultimate goal of the longitudinal study is to monitor the change of this image in the years before and after the titular year - 2021.In addition, paper aims to analyse how the residents' city image perception differs based on their sociodemographic characteristics. Based on this, the current study aims to contribute to the quite limited literature regarding the impact of the European Capital of Culture project on the city image perceived by local community. 
Impact of the European Capital of Culture Project on the Image of the City of Novi Sad -

the Perception of the Local Community

\section{Literature review}

\section{Perception of image by local community}

Image as well as destination/city image, are defined in different ways in various fields of study (Baloglu 1997; Baloglu and McCleary 1999; Gartner 1993; Kim and Richardson 2003) indicating that there is no one universal definition. One of the most cited was given by Crompton (1979), who defined an image as "the sum of beliefs, ideas and impressions that tourists have about a particular destination."

In the structure of destination image, there are two main dimensions: cognitive and affective (San Martín and Rodríguez del Bosque, 2008). A cognitive component means the knowledge and belief a person has about the attributes and characteristics of an object or a place (Pike and Ryan 2004; Stepchenkova and Mills 2010). The affective component represents the emotions and feelings an individual has about that object/place (Kim and Richardson 2003).

Although sparse, exciting tourism literature on residents' perception of destination image suggests discrepancies between image perceptions held by residents and other stakeholders such as tourists (Henkel et al., 2006; Sternquist-Witter, 1985; Stylidis et al., 2014; Stylidis et al., 2017) and the influence of such perception on local people's future intended behavior (Bigné et al., 2005; Schroeder, 1996). For instance, Stylidis et al. (2014) concluded that locals tend to have the least favorable perception of the city's image compared to other stakeholder groups, namely tourists and tourism employees/owners. Moreover, such finding was confirmed in the later work of Stylidis et al. (2017), which showed that residents, compared to tourists, givelower rankings to the place's image attributes. Furthermore, Bigné et al. (2005) examined whether the image of the residing region affects residents' intended behavior, and results confirmed imageas a predictor of both intention to recommend the regionas a tourist destination and willingness to return to the region.

Sometimes, dissimilarity in image perception may result in conflicts between different stakeholder groups (Byrd et al., 2009; Henkel et al., 2006), thus causing disbalance in harmony and cohesiveness and jeopardizing destination brand and image (Csaba, 2005). To avoid such scenarios, some authors point out the necessity to detect and incorporate every interest groups' perceptions and images (Merrilees et al., 2012; Reid et al., 2004; Stylidis et al., 2014). Yet another reason to investigate locals' perception of the place image lies in the fact that they act as destination ambassadors from tourists' perspective (Hudson, Hawkins, 2006; Leisen, 2001; Schroeder, 1996) and influence how tourists perceive destination image, their decision to travel and experience the site (Gallarza et al., 2002; Walls et al., 2008). Thus, the idea of expanding branding and marketing strategies with residents' perception of the image may contribute to enhancing visitors' experience, as residents possess relevant local knowledge of the destination (Campelo et al., 2014; Stylidis et al., 2016). Besides, tourism literature indicates the importance of detecting any negative perceptions of the image attributes held by residents, as they may endanger tourism development and opportunities for both potential tourists or residents to visit the place (Ward, 1998; Stylidis et al., 2014). In addition, some authors (Stylidis, Terzidou 2014; Nunkoo, Gursoy 2012) agreed on the crucial role of local people's support in achieving successful destination development and marketing (Stylidis et al., 2016).

Another criticism of literature related to image perception by residents refers to the application of models that better correspond to tourists' assessment of the image and neglect residents' complex associations of the place where they live and work (Green, 2005). In contrast to tourists, residents form a broader assessment of a tourist place, as for them, it means more than 
a destination for a vacation (Hudson, 1988; Stylidis et al., 2016). Consequently, some authors (Stylidis et al., 2014; Stylidis et al., 2016) included community-related items into the measurement model to gain better insight into residents' evaluation of their residing place's image. They have put emphasis on the importance of incorporating specific attributes relevant to residents, aside from ones corresponding to tourists.

Similarly, the presence of residents and their integral role in the brand formation of place have been acknowledged in the field of place branding literature (Braun et al., 2013; Freire, 2009). However, this area's practitioners have been criticized often, as their idea of including residents in the project of place branding did not go beyond mere consultation about their brand associations (Bennett, Savani, 2003; Zenker, Erfgen, 2014). Thus, Zenker and Erfgen (2014) suggest an approach to the place branding process, which embraces the presence of residents and points out the previously mentioned consultation as the first step of this process. Because locals can express a large number of different associations (Zenker, Beckmann, 2013), it is of great importance to select the optimal ones (Pirck, 2005). Another thing equally important is to examine how selected associations as key components influence local people's satisfaction or attractiveness of the place (Zenker et al., 2013). The following step refers to providing the presence of public place marketing agencies, which will support the residents in their ideas, previously presented in the application process. As for the final step, it is of great importance to monitor the implemented project and measure results, as results will show whether taken activities have influenced the desired brand perception (Zenker et al., 2013).

Based on these findings, taking into account the role of the local community as an important stakeholder of the city it is evident that understanding the way they perceive the city's image is of a great importance. Hence, the current study aims to determine locals' assessment of their residing place's cognitive, affective, and overall images in order to define the areas that are recognized and appreciated enough, as well as those that are still undeveloped or need more attention. Once a hierarchy of assessed destination image items is established, it will provide a focus for future stakeholders" actions.

\section{Research on image in European Capitals of Culture}

During the year 2001, which was the titular year for Rotterdam, Richins and Wilson (2004) conducted research among residents, domestic and international tourists, and results extracted some interesting findings concerning the effect of project ECoC on destination image perception. Firstly, as results indicated generally high scores on respondents' assessment of culture and art aspects of the city's image, authors agreed on the project's success in enhancing the city's culture and art awareness. Secondly, the authors pointed out a positive relationship between the assessment of the event program and perception of the city as a tourist destination, thus emphasizing the positive influence of the project ECoC on Rotterdam's image. Besides, they have found another positive correlation between the city's image as a place with events and perception of it as a tourist destination. Finally, as researchers also carried out interviews with tourism stakeholders on this topic, obtained responses suggested that, generally, tourism stakeholders agreed on the positive influence of the project on the city's image (Richins, Wilson, 2004). Likewise, Farmaki et al. (2019) carried out semi-structured interviews with residents of Pafos, which held the title of European Capital of Culture for 2017, to determine how locals perceive the influence of the ECoC project on their city's image. The research was conducted during the titular year, and results indicated respondents' positive assessments of the ECoC initiative's impact on destination image as a crucial benefit of the project.Shuk- 
la et al. (2006) carried out their research a couple of years before the upcoming ECoC event in Liverpool in 2008, focusing on both destination image and tourists' associations of the city's attractions. The authors examined whether Liverpool's tangible or intangible attractions tourists more favorably associate with the city's image, thus using their assessment as segmentation criteria for destination image and providing tourism stakeholders with practical implications regarding the ECoC event.Also, one year before the titular year, van der Steen and Richards (2019) examined residents' attitudes and opinions in relation to the ECoC event in Valletta in 2018, whereby one item of benefits section referred to the image and results confirmed that, among other, the more residents perceived potential benefits from the event, the more they will support the project.Aside from the previous research findings, several authors in the field of event tourism (Arnegger, Herz, 2016; Grix, 2013; Lui, 2014; Smith, 2012) also support the idea of enhancement of destination image as one of the positive consequences of event management.

After the literature analysis, the notion of the positive impact of the $\mathrm{ECoC}$ event on host cities' images and tourism stakeholders' attitudes has come to the light. Therefore, this paper focuses on residents' perception of the city's image in the years that precede the event, so when the ECoC event finishes, divergences in the city's image assessment could be compared with the previous state, in order to detect the progress and the real impact of ECoC on the city image in the eyes of residents.

\section{Sociodemographic characteristics and image perception}

A considerable amount of tourism literature has recognized sociodemographic characteristics as a valuable determinant of the formation of destination image perception (Baloglu, 1997; Baloglu, McCleary, 1999; Beerli, Martín, 2004; Božić, 2016; Henkel et al., 2016; Hui, Wan, 2003; Richards, Wilson, 2004; Stern, Krakover, 1993; Walmsey, Jenkins, 1993). Stern and Krakover (1993) examined whether respondents' education level affects the relationship between assessment of cognitive, affective, and overall images, and results confirmed differences among different education groups. Baloglu (1997) investigated the influence of German tourists' sociodemographic variables on their perception of the USA's image, and results indicated age, marital status, and occupation as significant predictors of the perceived image. In later research, Baloglu and McCleary (1999) investigated whether respondents' age and education level affect image perception of Greece, Turkey, Italy, and Egypt. Their results showed that both age and education level affect tourists' assessment of the cognitive image. Hui and Wan (2003) carried out their study among international tourists visiting Singapore, and findings confirmed the positive influence of age, education, and country origin on shaping the perception of destination image attributes. In the work of Beerli and Martín (2004), differences in image perception were detected among first-time and repeat tourists of different sociodemographic backgrounds. In specific, gender was found to influence how first-time tourists perceive both cognitive and affective images, while it only affected repeat tourists' perception of the cognitive image.Furthermore, age was confirmed to shape cognitive image perception for both firsttime and repeat tourists. On the other hand, results indicate education level has an effect on repeat tourists' perception of the affective image. Similarly, social class was confirmed to be a predictor of first-time tourists' cognitive image perception. Results also suggest that respondents' country origin influences how both first-time and repeat tourists perceive cognitive and affective image attributes. Moreover, Božić (2016) emphasized tourists' place of residency as a determinant of their perception of the cognitive image. Finally, on a combined sample of tour- 
ists and residents, Henkel et al. (2016) confirmed the influence of gender, age, and marital status on the evaluation of various items relating to the destination image. Richards and Wilson (2004) also confirmed sociodemographic variables such as gender, age, employment status, and country origin as significant determinants of both visitors' and residents' image perception.

Based on these, the present study aims to examine whether residents' sociodemographic characteristics influence how they perceive their residing city's cognitive, affective, and overall image. In that manner, any differences in image perceptionby different local community segments, will be detected. Hence, relevant tourism employees may take advantage of such knowledge and focus on perception gaps to reduce any negative assessments of specific image areas and establish a satisfactory level of all image components.

\section{Methodology}

\section{Study sample}

A total of 797 respondents, the citizens of Novi Sad and Petrovaradin participated in the study. The age limit for including respondents in the survey was 18 years. To get reliable data, the sample was stratified, by gender, age and geography (according to the city municipalities). There is quite an equal number of male and female respondents. The average age of the respondents is 45.6 years. The majority of respondents are employed (55\%), which corresponds to their age structure. The largest numbers of respondents have completed secondary school (52.4\%), with no significant difference in the education of women and men.The basic sociodemographic characteristics of the respondents are shown in Table 1.

Table 1. Sociodemographic characteristics of respondents

\begin{tabular}{|c|c|c|c|}
\hline \multicolumn{2}{|c|}{ Gender } & \multicolumn{2}{c|}{ Education } \\
\hline Male & $52 \%$ & Elementary school & $3.4 \%$ \\
\hline Female Age & $48 \%$ & Secondary school & $52.4 \%$ \\
\hline \multirow{2}{*}{ Average age - 45.6 years } & Higher school and faculty & $36.5 \%$ \\
\cline { 2 - 4 } & \multicolumn{2}{c|}{ Employment status } \\
\cline { 2 - 4 } & \multicolumn{2}{c|}{ Employed } & $54.8 \%$ \\
\hline Monthly income & Unemployed & $11.0 \%$ \\
\hline \multirow{2}{*}{ Below average } & $36.5 \%$ & Retired & $19.7 \%$ \\
\hline Average & $42.1 \%$ & Pupil/Students & $9.8 \%$ \\
\hline Above average & $21.4 \%$ & Housewife & $4.6 \%$ \\
\hline
\end{tabular}

\section{Procedure}

Data collection was performed by a survey on a sample of citizens living in the municipalities of Novi Sad and Petrovaradin. The survey was conducted by trained interviewers during April and May 2018. Participation in the survey was voluntary and respondents were informed about the main purpose of the research. 


\section{Instrument}

The questionnaire was used to collect the data for the study. The questionnaire consisted of two parts. The first part included socio-demographic characteristics of respondents, while the second part focused on the perception of the city image by the local community. The second part of the questionnaire measured cognitive, affective and overall image. The cognitive image was measured by the scale based on the City Brand Index (Anholt, 2006). The statements were assessed on a five-point Likert scale (1-strongly disagree, 5 - strongly agree). The affective image was measured by assessing 4 bipolar pairs (Relaxing - Stressful, Pleasant - Unpleasant, Exciting - Boring, Lively - Sleepy) on a scale of 1 to 5 by which respondents assessed which attribute better describestheir affective experience of Novi Sad. The overall image was measured on a rating scale of 1 - very negative to 5 - very positive.

\section{Statistical analysis}

Data were processed by SPSS (Statistical Software for Social Sciences) 23. The analysis used in the study is independents sample t-test, ANOVA test and Pearson correlation test.

\section{Results and discussion}

To assess the current perception of the image of the city of Novi Sad, the citizens were asked to evaluate 18 statements related to the cognitive image of the city. Citizens rated their level of agreement with the statements on a scale from 1 to 5 (1-I do not agree at all, 5 - I completely agree). Mean values with standard deviations are shown in Table 2.

Table 2. Perception of the cognitive image by the citizens of Novi Sad

\begin{tabular}{|c|c|c|}
\hline Statements of cognitive image Novi Sad... & Mean value & Std. deviation \\
\hline$\ldots$ has a pleasant climate & 3.97 & 0.994 \\
\hline$\ldots$ is an attractive tourist destination & 4.04 & 0.873 \\
\hline ... seems like a pleasant place to live & 4.35 & 0.715 \\
\hline$\ldots$ is an attractive place to invest and start a business & 3.76 & 0.955 \\
\hline ..is an attractive place for education & 4.22 & 0.859 \\
\hline$\ldots$ is a place where it's easy to find a job & 2.65 & 1.158 \\
\hline $\begin{array}{l}\text {... is the city where the standard of public institutions is high } \\
\text { (schools, faculties, hospitals ...) }\end{array}$ & 3.38 & 1.266 \\
\hline ... has adequate local transportation & 3.58 & 1.141 \\
\hline ... has enough quality accommodation facilities & 3.78 & 0.962 \\
\hline ... there are many interesting events & 3.95 & 0.936 \\
\hline ... people are kind and hospitable & 4.20 & 0.835 \\
\hline ... the city seems safe and secure & 3.61 & 1.122 \\
\hline$\ldots$ has interesting museums and galleries & 3.82 & 0.933 \\
\hline .has interesting cultural and historical attractions & 4.04 & 0.839 \\
\hline ... has a good gastronomic offer & 4.33 & 0.777 \\
\hline ... has a dynamic and good nightlife & 4.04 & 0.900 \\
\hline ... has a variety of tourist attractions & 4.01 & 0.898 \\
\hline ... has an interesting architecture & 4.03 & 0.903 \\
\hline
\end{tabular}


The highest mean values of answers are related to the following statements: Novi Sad acts as a pleasant place to live, has a good gastronomic offer, is an attractive place for education and People are kind and hospitable (items with an average value over 4.20). This is an expected finding, considering that Novi Sad is a university city, known for its friendly population, a good gastronomic offer that was created under the influence of the multicultural environment of the city, as well as a medium-sized city pleasant for the life of citizens (Vujičić et al., 2020). Besides, current findings showing generally high mean scores (around 4) for assessment of the city as a place that isan attractive tourist destination and has an interesting architecture could be associated with previous one (Stylidis et al., 2016) that indicates residents' appreciation for the environment that is aesthetically appealing, which, as such, contributes to their better performance of daily activities. Another similarity exists with previous studies that indicated high locals' perception of the friendly environment of their residing place or country (Henkel et al., 2006). Moreover, the way locals perceive a friendly environment becomes the key element in shaping their evaluation of the destination (Freire, 2009).

The lowest rated attributes of the city by citizens are: It is easy to find a job, the standard of public institutions is high (schools, colleges, hospitals ...), adequate local transport, and the city seems safe and secure - so the attributes concerning the standard of living in the city point to key unresolved issues that city residents are dissatisfied with. The fact that residents less perceived the city as a place that has adequate local transportation (3.58) and where it's easy to find a job (2.65) could be associated with the findings of Stylidis et al. (2016) that pointed out locals' critical assessment and low scores on convienient transportation and good job opportunities in the city.Besides, it is not surprising that people who involve more closely with a brand show tendency to be more critical in its assessment (May, 1973).

When it comes to tourism and culture, it is interesting to note that statements such as the city has interesting museums and galleries, interesting events, as well as quality accommodation facilities,which are rated with the average score below 4. Considering the fact that locals tend to have a lower perception of Novi Sad as a city that has enough quality accommodation facilities, we may find the link with the prior research (Stylidis et al., 2017) that pointed out residents' lower ratings on the assessment of Amenities items such as quality hotels, appealing restaurants, and excellent service quality. Besides, previous literature suggests that city's cultural activities are of secondary importance when it comes to influencing residents' attitudes about the city brand (Merrilees et al., 2009; Braun et al., 2013). The nightlife, the city has a variety of attractions and the interesting architecture are much better rated by the citizens.

The largest average standard deviations can be noticed in the assessment of the following statements: the standard of public institutions is high (schools, faculties, hospitals ...), Novi Sad has an adequate local transport, it is easy to find a job, and the city seems safe and secure, and these are also the items that are the lowest rated. This indicates that there is a need for additional research because it raises the question of why there is the largest deviation in the items that are rated the lowest and whether this phenomenon is related to differences in sociodemographic characteristics of respondents.

To evaluate the affective image, the citizens were offered 4 bipolar pairs of attributes, assessing which of pairs better describe their affective experience of Novi Sad. The attributes were rated on a scale from -2 to +2 . The results show that all mean values are much closer to positive attributes such as relaxing, pleasant, exciting, lively (Table 3). Of the 4 offered pairs of attributes, Novi Sad is rated the most as a pleasant city.Such finding is in line with the previous one that emphasizes residents mostly assessed their residing city as pleasant (Stylidis et al., 2017). 
Table 3. The assessment of affective image

\begin{tabular}{|c|c|c|c|}
\hline & Mean value & Std. deviation & \\
\hline Relaxing & 2.11 & 0.969 & Stressful \\
\hline Pleasant & 1.78 & 0.912 & Unpleasant \\
\hline Exciting & 2.14 & 0.944 & Boarding \\
\hline Lively & 2.15 & 0.992 & Sleepy \\
\hline
\end{tabular}

The mean value of the overall image of the city of Novi Sad is 4.01 (Std. .811), indicating the citizens believe that Novi Sad has a positive overall image.

\section{Differences in image perception based on sociodemographic characteristics}

To check whether respondents differ in their image perception based on sociodemographic characteristics (gender, age, education, monthly income, employment status and marital status), an independent sample t-test, ANOVA test and Pearson test of correlations were applied.

An independent sample t-test showed no significant results in image perception between male and female respondents. Further on, the ANOVA test was applied to test the differences between respondents of different education, monthly income, employment status and marital status).

The findings indicate that respondents of different education levels differ in their perception of Novi Sad city image. Differences were found regarding the perception of It is easy to find a job ( $F=4.407, p=.004)$, People are friendly and hospitable $(F=2.908, p=.002)$, Novi Sad has a dynamic nightlife ( $F=6.737, p=.008)$ and Novi Sad has interesting architecture ( $F=3.978, p=.008)$.

LSD post hoc test showed that respondents who have finished secondary school consider people in Novi Sad are more friendly and hospitable than respondents who have finished higher school and who have higher education (faculty, master, Ph.D.). People who have finished elementary school more than all other education groups consider that it is easy to find a job in Novi Sad.

When it comes to respondents of different monthly income, differences were found in the perception of Novi Sad is attractive tourist destination $(F=4.468, p=.004)$ City is safe and secure ( $F=5.064, p=.002)$, Novi Sad has interesting cultural and historical attractions ( $F=3.207, p=.023)$, Novi Sad has a dynamic nightlife ( $F=15.281, p=.002)$, and Novi Sad has interesting architecture $(F=3.166, p=.024)$.

LSD post hoc test showed that respondents with above-average monthly income consider Novi Sad as more safe and secure that respondents with average and below-average income. The same was found for the perception of interesting cultural and historical attractions and perception of Novi Sad as an attractive tourist destination. When it comes to nightlife and interesting architecture, respondents with bellow average income the least consider that Novi Sad has a dynamic and good nightlife.

Finally, respondents of different employment status differ in perception of Novi Sad as the city where it is easy to find a job ( $F=4.225, p=.001)$, it has interesting museums and galleries $(F=2.437, p=.033)$, and it has a dynamic and good nightlife $(F=20.581, p=.000)$. LSD post hoc test showed that respondents unemployed people less than all other categories consider Novi Sad as a place where it is easy to find a job and as a place with interesting museums and galleries. Students and pupils more than other categories consider Novi Sad as a city with dynamic and good nightlife. Of course, the local population is not homogenous, and people of different 
employment statuses, as well as various life-stages, differ in assessments of their residing city's brand image (Henkel et al., 2006).

When it comes to respondents' age, significant correlations were found only in case of perception of Novi Sad as a city with good local transport $(r=.075, p=.034)$ and the city with dynamic and good nightlife $(r=-.398, p=.0 o o)$. Such findings indicate that the older the respondents are, the more they consider Novi Sad as a city with good local transport, and the less they consider Novi Sad as the city with dynamic and good nightlife. Although Henkel et al. (2006) investigated differences in perception on the sample of both residents and visitors of different ages, findings suggest that older respondents have a lower evaluation of the importance of nightlife and entertainment as part of the destination image. A similar finding was confirmed in the work of Richards and Wilson (2004), where younger respondents were found to more positively associate the city with nightlife.

\section{Conclusion}

Encouraging the participation of the local community in the economic, social and cultural life of the city is one of the important goals of the European Capital of Culture. In this regard, the perception of the city image by the local community is an extremely important indicator of the success of the European Capital of Culture. Thus, continuous monitoring of the city's cognitive and affective image is of great importance. The results showed that the current image of the city is positive, but also that there is still a lot of room for improvement. The basic conclusions can be stated as follows:

On one hand, citizens still do not perceive the city as a stimulating business environment where it is easy to find a job and where there are good opportunities for investment, but on the other hand, they perceive the city as a pleasant place to live. Novi Sad residents also believe that there is a need for additional investment in tourism and public infrastructure, public institutions and the functioning of local transport. They perceive the diversity of tourist attractions, architecture, friendly population, gastronomic offer and nightlife as the main advantages of the city. When it comes to culture, the results indicate that there is room for improvement in the field of events and museums and galleries offer, and it is assumed that the perception of these items will change in the coming years, which will be monitored by a longitudinal study. It is expected that the affective image, although already positive, will change over time, in the direction of a greater perception of the city as exciting and lively, which will contribute to the cultural program and events which will increase by 2021 .

The longitudinal study will cover the period from 2017 to 2023 , and future research will also include spatial analyzes that should indicate whether there are differences in the perception of the city's image between citizens living in different parts of the city.

\section{Acknowledgment}

This research is supported by the Foundation "Novi Sad 2021" and the project Novi Sad European Capital of Culture 2021. 


\section{References}

Anholt, S. 2006. The Anholt-GMI city brands index: How the world sees the world's cities. Place branding 2(1), 18-31.

Arnegger, J., Herz, M. 2016. Economic and destination image impacts of mega-events in emerging tourist destinations. Journal of Destination Marketing and Management 5(2), 76-85.

Baloglu, S. 1997. The relationship between destination images and sociodemographic and trip characteristics of international travelers. Journal of Vacation Marketing 3(3), 221-233.

Baloglu, S., McCleary, K.W. 1999. A model of destination image formation. Annals of Tourism Research 26(4), 868-897.

Beerli, A., Martín, J.D. 2004. Tourists' characteristics and the perceived image of tourist destinations: A qualitative analysis - a case study of Lanzarote, Spain. Tourism Management $25(5), 623-636$.

Bennett, R., Savani, S. 2003. The rebranding of city places: An international comparative investigation. International Public Management Review 4(2), 70-87.

Bigné, E.A., Sanchez, I.G., Sanz, S.B. 2005. Relationships among residents' image, evaluation of the stay and post-purchase behaviour. Journal of Vacation Marketing 11(4), 291-302.

Božić, S. (2016). The impact of tourist personality on destination brand and tourist behavior on example of the sites of the cultural route. Ph.D. Thesis, University of Novi Sad, Serbia. (In Serbian)

Braun, E., Kavaratzis, M., Zenker, S. 2013. My city-my brand: the different roles of residents in place branding. Journal of Place Management and Development 6(1), 18-28.

Byrd, E.T., Bosley, H.E., Dronberger, M.G. 2009. Comparisons of stakeholder perceptions of tourism impacts in rural eastern North Carolina. Tourism Management 30(5), 693-703.

Campelo, A.R., Aitken, R., Thyne, M., Gnoth, J. 2014. Sense of place: The importance of destination branding. Journal of Travel Research 53(2), 154-166.

Csaba, F.F. 2005. The limits of corporate branding: The application of branding to non-profit organizations and places. In: Schultz, M., Antorini, Y., Csaba, F.F. (Eds.) Corporate branding, Purpose/People/Process: Towards the Second Wave of Corporate Branding. Copenhagen Business School Press, Frederiksberg, 127-149.

Crompton J. L. 1979. An assessment of the image of Mexico as a vacation destination and the influence of geographical location upon that image. Journal of Travel Research 17(4),18-23.

Dinnie, K. 2011. Introduction to the theory of city branding. In: Dinnie, K. (Ed.)City Branding. Palgrave Macmillan, London, 3-7.

Farmaki, A., Christou, P., Saveriades, A., Spanou-Tripinioti, E. 2019. Perceptions of Pafos as European Capital of Culture: Tourism stakeholder and resident perspectives. International Journal of Tourism Research 21(2), 234-244.

Freire, J.R. 2009. Local people: A critical dimension for place brands. Journal of Brand Management 16(7), 420-438.

Gallarza, M.G., Saura, L.G., Garcia, H.C. 2002. Destination image: Towards a conceptual framework. Annals of Tourism Research 29(1), 56-78.

Gartner, W.C. 1993. Image formation process. Journal of Travel and Tourism Marketing 2 (2/3), 191-215.

Green, R. 2005. Community perceptions of environmental and social change and tourism development on the island of Koh Samui, Thailand. Journal of Environmental Psychology 25(1), 37-56.

Grix, J. 2013. Sport politics and the Olympics. Political Studies Review 11(1), 15-25. 
Henkel, R., Henkel, P., Agrusa, W., Agrusa, J., Tanner, J. 2006. Thailand as a tourist destination: Perceptions of international visitors and Thai residents. Asia Pacific Journal of Tourism Research 11(3), 269-287.

Hudson, M., Hawkins, N. 2006. A tale of two cities - A commentary on historic and current marketing strategies used by the Liverpool and Glasgow regions. Place Branding and Public Diplomacy 2(2), 155-176.

Hudson, R. 1988. Uneven development in capitalist societies: Changing spatial divisions of labour, forms of spatial organization of production and service provision, and their impacts on localities. Transactions of the Institute of British Geographers 13(4), 484-496.

Hui, T.K., Wan, T.W.D. 2003. Singapore's image as a tourist destination. International Journal of Tourism Research 5, 305-313.

Jovanović, T., Božić, S., Dinić, B.,Majstorović, N. 2017. Serbian adaptation of the brand personality scale (BPS): An application to tourism destinations. Applied Psychology 10(1), 37-61.

Keller, K.L. 1993. Conceptualizing, measuring, and managing customer-based brand equity. Journal of Marketing 57 (1), 1-22.

Kerr, G. 2006. From destination brand to location brand. Journal of Brand Management 13(45), 276-283.

Kim, H., Richardson L. S. 2003. Motion picture impacts on destination images. Annals of Tourism Research 30(1), 216-237.

Kovačić, S., Jovanović, T., Šagovnović, I. 2019b. Exploring the gap in destination image and destination personality perception between tourists and stakeholders - Case of Roman heritage sites in Serbia.Turizam 23(3), 133-144.

Kovačić, S., Milenković, N., Slivar, I., Rancic, M. 2019a. Shaping city brand strategies based on the tourists' brand perception: report on Banja Luka main target groups. International Journal of Tourism Cities 6(2), 371-396.

Leisen, B. 2001. Image segmentation: The case of a tourism destination. Journal of Services Marketing 15(1), 49-66.

Liu, Y.D. 2014. Socio-cultural impacts of major event: Evidence form the 2008 European Capital of Culture, Liverpool. Social Indicators Research 115(3), 983-998.

Lynch, K. 1960. The image of the city. MIT Press, Cambridge, MA.

Merrilees, B., Miller, D., Herington, C. 2009. Antecedents of residents' city brand attitudes. Journal of Business Research 62(3), 362-367.

Merrilees, B., Miller, D.,Herington, C. 2012. Multiple stakeholders and multiple city brand meanings. European Journal of Marketing 46(7-8), 1032-1047.

Nunkoo, R., Gursoy, D. 2012. Residents' support for tourism: An identity perspective. Annals of Tourism Research 39(1), 243-268.

Palmer, A., Koenig-Lewis, N., Jones, L.E.M. 2013. The effects of residents' social identity and involvement on their advocacy of incoming tourism. Tourism Management 38, 142-151.

Pike, S., and C. Ryan. 2004. Destination Positioning Analysis through a Comparison of Cognitive, Affective, and Conative Perceptions. Journal of Travel Research 42, 333-42.

Pirck, P. 2005. Markeistmachbar. PlanungEAnalyse 3(3), 2-6.

Reid, D.G., Mair, H., George, W. 2004. Community tourism planning: A self-assessment instrument. Annals of Tourism Research 31(3), 623-639.

Richards, G., Wilson, J. 2004. The impact of cultural events on city image: Rotterdam, cultural capital of Europe 2001. Urban Studies 41(10), 1931-1951. 
San Martín, H., and A. I. Rodríguez del Bosque. 2008. Exploring the cognitive-affective nature of destination image and the role of psychological factors in its formation. Tourism Management 29 (2), 263-277

Schroeder, T. 1996. The relationship of residents' image of their states as a tourist destination and their support for tourism. Journal of Travel Research 34(4), 71-73.

Shukla, P., Brown, J., Harper, D. 2006. Image association and European capital of culture: Empirical insights through the case study of Liverpool. Tourism Review 61(4), 6-12.

Smith, A. 2012. Events and urban regeneration: The strategic use of events to revitalize cities. Routledge, London.

Stern, E., Krakover, S. 1993. The formation of a composite urban image. Geographical Analysis $25,130-146$.

Stepchenkova, S., J. Mills. 2010. Destination image: a meta-analysis of 2000-2007 research. Journal of Hospitality Marketing and Management 19(6), 575-609.

Sternquist-Witter, B.S. 1985. Attitudes about a resort area: A comparison of tourists and local retailers. Journal of Travel Research 51(6), 687-703.

Stylidis, D., Belhassen, Y., Shani, A. 2014. Three tales of a city: Stakeholders' images of Eilat as a tourist destination. Journal of Travel Research 54(6), 702-716.

Stylidis, D., Shani, A., Belhassen, Y. 2017. Testing an integrated destination image model across residents and tourists. Tourism Management 58, 184-195.

Stylidis, D., Sit, J., Biran, A. 2016. An exploratory study of residents' perception of place image: The case of Kavala. Journal of Travel Research 55(5), 659-674.

Stylidis, D., Terzidou, M. 2014. Tourism and the economic crisis in Kavala, Greece. Annals of Tourism Research 44, 210-226.

Van der Steen, T., Richards, G. 2019. Factors affecting resident support for a hallmark cultural event: the 2018 European Capital of Culture in Valletta, Malta. Journal of Policy Research in Tourism, Leisure and Events. DOI: 10.1080/19407963.2019.1696352

Vasiljević, Đ., Božić, S., Vujičić, M., Stankov, U., Čikić, J., Ristić, D., Milenković, N. (2018). Attitudes of Novi Sad Residents Towards the Title European Capital of Culture (Novi Sad 2021) - Preliminary Results. 7th Biennial ITSA 2nd International TESA Conference, 6 10 August 2018, Pretoria, Republic of South Africa.

Vujičić, M., Stankov, U., Božić, S., Vasiljević, Đ. (2018). Perception of place image by inner-city and suburban residents - The Case of Novi Sad (Serbia). 7th Biennial ITSA 2nd International TESA Conference, 6 - 10 August 2018, Pretoria, Republic of South Africa. Available at: https://arcg.is/1qO8O5

Vujičić, M.D., Stamenković, I., Stankov, U., Kovačić, S., Vasiljević, Đ.A., Popov-Locke, J. 2020. What will prevail within citybreak travel, motivation or demotivation?: Case study of Novi Sad, Vojvodina, Serbia. GeographicaPannonica 24(1), 42-55.

Walls, A., Shani, A., Rompf, P.D. 2008. The nature of gratuitous referrals in tourism: Local residents' perspectives. International Journal of Contemporary Hospitality Management 20, 647-663.

Walmsley, D.J., Jenkins, J.M. 1993. Appraisive images of tourist areas: Application of personal construct. Australian Geographer 24(2), 1-13.

Ward, S. 1998. Selling Places: The Marketing and Promotion of Towns and Cities 1850-200o. Routledge, London.

Zenker, S., Beckmann, S.C. 2013. My place is not your place - different place brand knowledge by different target groups. Journal of Place Management and Development 6(1), 6-17. 
Zenker, S., Braun, E., Petersen, S. 2017. Branding the destination versus the place: The effects of brand complexity and identification for residents and visitors. Tourism Management 58, 15-27.

Zenker, S., Erfgen, C. 2014. Let them do the work: a participatory place branding approach. Journal of place management and development 7(3), 225-34.

Zenker, S., Petersen, S. 2014. An integrative theoretical model for improving resident-city identification. Environment and Planning 46(3), 715-729.

Zenker, S., Petersen, S., Aholt, A. 2013. The Citizen Satisfaction Index (CSI): evidence for a four basic factor model in a German sample. Cities 31, 156-164. 